\title{
PENGARUH MODEL THINK PAIR SHARE TERHADAP HASIL BELAJAR SISWA DALAM PEMBELAJARAN SEJARAH KELAS X SMA SWASTA DELI MURNI DELITUA TAHUN PELAJARAN 2019/2020
}

\author{
Oleh : \\ Klara Agustini Ginting \\ Ponirin
}

\begin{abstract}
Abstrak
Penelitian ini bertujuan untuk mengetahui pengaruh model Think Pair Share dalam meningkatkan hasil belajar sejarah siswa. Penelitian ini merupakan penelitian kuantitatif dengan desain penelitian eksperimen, yaitu ada perbedaan pelakuan antara kelas eksperimen dan kelas kontrol agar dapat dilihat perbedaannya. Populasi penelitian ini adalah kelas X IIS SMA Swasta Deli Murni Delitua yang terdiri dari 5 kelas dengan jumlah seluruh siswa 168 orang. Pengambilan sampel dalam penelitian ini menggunakan teknik acak atau random sampling, dimana kelas eksperimen adalah X IIS 1 yang diajarkan dengan menggunakan model Think Pair Share dan kelas kontrol adalah kelas X IIS 2 yang diajarkan dengan metode ceramah. Berdasarkan hasil penelitian nilai rata-rata siswa pada kelas X IIS 1 adalah sebesar 81,2 sedangkan nilai rata-rata kelas X IIS 2 sebesar 66,16. Adanya perbedaan hasil belajar tersebut juga terbukti melalui pengujian hipotesis dengan menggunakan uji-t dan taraf kepercayaan $\alpha=0,05$ dimana $t_{\text {hitung }}>t_{\text {tabel }}$ yaitu 6,10645> 1,6723 dengan demikian dalam penelitian ini $H_{0}$ ditolak dan $H_{a}$ diterima, sehingga dapat disimpulkan bahwa ada perbedaan hasil belajar yang signifikan antara model Think Pair Share dengan metode ceramah yang lebih tinggi hasil belajar yang menggunakan model Think Pair Share.
\end{abstract}

Kata Kunci: Model Think Pair Share, Hasil Belajar Sejarah 


\section{PENDAHULUAN}

Pendidikan merupakan suatu bagian yang tidak terlepas dari kehidupan manusia, yang mana pendidikan itu merupakan peran yang sangat penting bagi setiap proses peningkatan kemampuan dan daya saing suatu bangsa dimata dunia dan melalui pendidikan setiap manusia berusaha mengembangkan potensi yang dimilikinya. Adapun tujuan Pendidikan Nasional yang tercantum dalam UndangUndang No. 20 tahun 2003 tentang Sistem Pendidikan Nasional ; pendidikan bertujuan untuk mengembangkan potensi siswa agar menjadi manusia yang beriman dan bertakwa kepada Tuhan Yang Maha Esa, berakhlak mulia, sehat, berilmu, cakap, kreatif, mandiri dan menjadi warga Negara yang demokratis serta bertanggung jawab.

Berdasarkan observasi yang dilakukan penulis di SMA Swasta Deli Murni Delitua. Penulis melihat bahwa guru masih menggunakan model konvensional, sehingga proses pembelajaran berlangsung satu arah saja. Dimana guru menerangkan dan siswa mendengarkan lalu mencatat, sehingga siswa bersifat pasif dalam belajar. Akibatnya siswa merasa bosan dan kurang tertarik belajar sejarah sehingga hasil belajar sejarah siswa rendah. Rendahnya hasil belajar siswa dibuktikan dengan masih banyaknya siswa yang belum mencapai nilai kriteria ketuntasan minimal (KKM) yang telah ditetapkan sekolah untuk mata pelajaran sejarah yaitu 75. Pada kenyataannya nilai rata-rata siswa di sekolah tersebut yaitu 65.

Berdasarkan permasalahan diatas maka salah satu solusinya adalah menggunakan strategi belajar mengajar yang inovatif. Hal ini dapat diwujudkan dengan model pembelajaran dalam proses pembelajarannya. Guru dapat memilih dari sekian banyak model pembelajaran yang ada untuk dapat digunakan dalam proses belajar mengajar yang tentunya harus juga dikondisikan dengan materi dan kemampuan siswa.

Salah satu model pembelajaran yang dapat digunakan adalah model Think Pair share. Think Pair Share adalah strategi diskusi kooperatif yang dikembangkan oleh Frank Lyman dari Universitas Maryland pada tahun 1981. Model Think Pair 
Share merupakan suatu model pembelajaran kooperatif yang memberi siswa waktu untuk berpikir dan merespon serta saling bantu sama lain. Model ini memperkenalkan ide "waktu berpikir atau waktu tunggu" yang menjadi faktor kuat dalam meningkatkan kemampuan siswa dalam merespon pertanyaan (Shoimin: 2014; 208).

Metode penelitian yang digunakan adalah Quasi Eksperimen. Quasi Eksperimen diartikan sebagai penelitian yang mendekati eksperimen atau eksperimen semu. Jenis penelitian ini bertujuan untuk mengungkapkan hubungan sebab akibat dengan melibatkan kelas kontrol dan eksperimen. Sampel dalam penelitian ini adalah sebagian anggota populasi yang diambil menggunakan teknik Cluster random sampling dengan cara random sebanyak dua kelas yaitu kelas eksperimen (kelas X IIS 1 dengan 30 siswa) dan kelas kontrol (kelas X IIS 2 dengan 30 siswa). Kelas eksperimen menngunakan model Think Pair Share, sedangkan kelas kontrol menggunakan model konvensional.

\section{PEMBAHASAN}

Penelitian ini mengambil 2 kelas sebagai sampel dari populasi. Kelas yang menjadi sampel adalah kelas X IIS 1 ( Siswa ) sebagai kelas eksperimen dan Kelas X IIS 2 sebagai kelas kontrol. Kelas eksperimen diberikan perlakuan menggunakan model pembelajaran Think Pair Share, sedangkan kelas kontrol diberikan perlakuan menggunakan model konvensional. Adapun hasil penelitian yang diperoleh adalah sebagai berikut :

Data nilai pretest siswa pada kelas eksperimen yaitu X IIS 1 dan kelas kontrol yaitu X IIS 2 sebagai berikut :

\section{Tabel 1 .}

Hasil Pretes Kelas Eksperimen (X IIS 1)

\begin{tabular}{|l|l|l|l|l|l|l|l|}
\hline Interval & F & Fk & Tb & Ta & $\begin{array}{l}\text { Nilai } \\
\text { Tengah }\end{array}$ & $\begin{array}{l}\text { Rata- } \\
\text { rata }\end{array}$ & $\begin{array}{l}\text { Standar } \\
\text { Deviasi }\end{array}$ \\
\cline { 1 - 5 } $30-36$ & 1 & 1 & 29,5 & 35,5 & 33 & 52,6 & 7,9 \\
\cline { 1 - 5 } $37-42$ & 4 & 5 & 36,5 & 41,5 & 39,5 & & \\
\hline $43-48$ & 1 & 6 & 42,5 & 47,5 & 45,5 & & \\
\hline
\end{tabular}




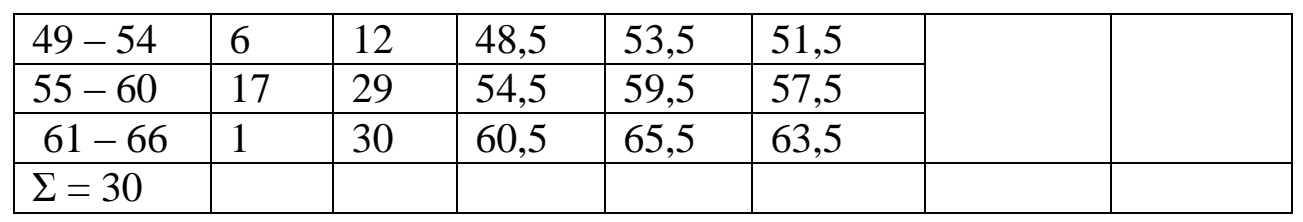

Tabel diatas adalah tabel yang menunjukkan hasil pretest pada kelas eksperimen yang berjumlah 30 siswa, dengan dengan interval nilai 30 - 36 dengan jumlah frekuensi 1, interval nilai 37 - 42 dengan jumlah frekuensi 4, interval nilai 43 48 dengan jumlah frekuensi 1, interval nilai 49 - 54 dengan jumlah 6, interval nilai 55 - 60 dengan jumlah frekuensi 17, intrval nilai 61- 66 dengan jumlah 1 dengan nilai ratarata adalah 52,6 serta standar deviasi 7,9.

Tabel 2

Hasil Pretes Kelas Kontrol (X IIS 2 )

\begin{tabular}{|c|c|c|c|c|c|c|c|}
\hline Interval & $\mathbf{F}$ & Fk & $\mathbf{T b}$ & $\mathbf{T a}$ & $\begin{array}{l}\text { Nilai } \\
\text { Tengah }\end{array}$ & $\begin{array}{l}\text { Rata- } \\
\text { rata }\end{array}$ & $\begin{array}{l}\text { Standar } \\
\text { Deviasi }\end{array}$ \\
\hline $40-45$ & 3 & 3 & 39,5 & 44,5 & 42,5 & \multirow[t]{6}{*}{54,3} & \multirow[t]{6}{*}{9,7} \\
\hline $46-51$ & 8 & 11 & 45,5 & 50,5 & 48,5 & & \\
\hline $52-56$ & 7 & 18 & 51,5 & 55,5 & 54 & & \\
\hline $57-61$ & 11 & 29 & 56,5 & 60,5 & 59 & & \\
\hline $62-66$ & 0 & 29 & 61,5 & 65,5 & 64 & & \\
\hline $67-71$ & 1 & 30 & 66,5 & 70,5 & 69 & & \\
\hline$\Sigma=30$ & & & & & & & \\
\hline
\end{tabular}

Tabel diatas adalah tabel yang menunjukkan hasil pretest pada kelas kelas kontrol yang berjumlah 30 siswa, dengan interval nilai 40 - 45 dengan jumlah frekuensi 3 , interval nilai 46 - 51 dengan jumlah frekuensi 8, interval nilai $52-56$ dengan jumlah frekuensi 7, interval nilai 57 - 61 dengan jumlah 11, interval nilai 62 - 66 dengan jumlah frekuensi 0, interval 67-71 dengan jumlah frekuensi 1 dan dengan nilai rata-rata adalah 54,3 dan standar deviasi 9,7. 


\section{Diagram 1}

Perbandingan Hasil pre test kelas eksperimen dan kelas kontrol

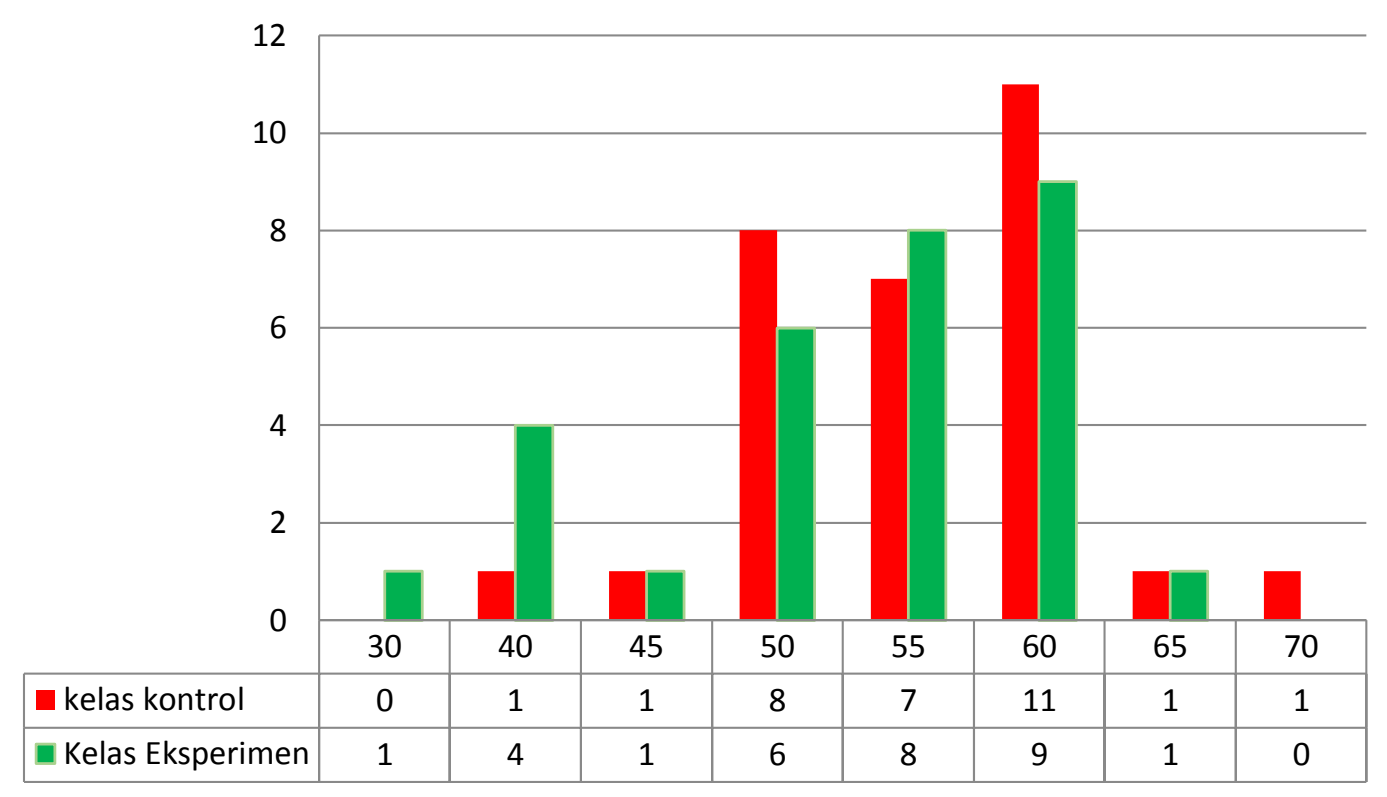

Berdasarkan gambar diagram batang diatas, nilai pretest kelas eksperimen berbeda dengan nilai pretest kelas kontrol. Hal dapat diketahui dari diagram yang ditunjukkan.

Data nilai posttest siswa pada kelas eksperimen yaitu X IIS 1 dan kelas kontrol yaitu X IIS 2 adalah sebagai berikut :

Tabel 4.3

Hasil Nilai Posttest Kelas Eksperimen

\begin{tabular}{|c|c|c|c|c|c|c|c|}
\hline Interval & $\mathbf{F}$ & Fk & $\mathbf{T b}$ & $\mathbf{T a}$ & $\begin{array}{l}\text { Nilai } \\
\text { Tengah }\end{array}$ & $\begin{array}{l}\text { Rata- } \\
\text { rata }\end{array}$ & $\begin{array}{l}\text { Standar } \\
\text { Deviasi }\end{array}$ \\
\hline $70-73$ & 1 & 1 & 69,5 & 72,5 & 71,5 & \multirow[t]{6}{*}{81,2} & \multirow[t]{6}{*}{11,6} \\
\hline $74-77$ & 7 & 8 & 73,5 & 76,5 & 75,5 & & \\
\hline $78-80$ & 7 & 15 & 77,5 & 79,5 & 79 & & \\
\hline $81-83$ & 0 & 15 & 80,5 & 82,5 & 82 & & \\
\hline $84-87$ & 8 & 23 & 83,5 & 86,5 & 85,5 & & \\
\hline $88-90$ & 7 & 30 & 87,5 & 89,5 & 89 & & \\
\hline$\Sigma=30$ & & & & & & & \\
\hline
\end{tabular}


Tabel diatas adalah tabel yang menunjukkan hasil posttest pada kelas eksperimen yang berjumlah 30 siswa, dengan interval nilai 70 - 73 dengan jumlah frekuensi 1, interval nilai 74 - 77 dengan jumlah frekuensi 7, interval nilai 81 - 83 dengan jumlah frekuensi 0 , interval nilai 84 - 87 dengan jumlah 8 , interval 88-90 dengan jumlah frekuensi 7 dan nilai rata-rata adalah 81,2 serta standar deviasi 11,6.

Tabel 4.4

Hasil Nilai Post test Kelas Kontrol

\begin{tabular}{|c|c|c|c|c|c|c|c|}
\hline Interval & $\mathbf{F}$ & Fk & $\mathbf{T b}$ & $\mathbf{T a}$ & $\begin{array}{l}\text { Nilai } \\
\text { Tengah }\end{array}$ & $\begin{array}{l}\text { Rata- } \\
\text { rata }\end{array}$ & $\begin{array}{l}\text { Standar } \\
\text { Deviasi }\end{array}$ \\
\hline $40-45$ & 3 & 3 & 39,5 & 44,5 & 42,4 & \multirow[t]{6}{*}{66,16} & \multirow[t]{6}{*}{8,57} \\
\hline $46-51$ & 2 & 5 & 45,5 & 50,5 & 48,5 & & \\
\hline $52-57$ & 2 & 7 & 51,5 & 56,5 & 54,5 & & \\
\hline $58-63$ & 0 & 7 & 57,5 & 62,5 & 60,5 & & \\
\hline $64-69$ & 7 & 14 & 63,5 & 68,5 & 66,5 & & \\
\hline $70-75$ & 16 & 30 & 69,5 & 74,5 & 72,5 & & \\
\hline$\Sigma=30$ & & & & & & & \\
\hline
\end{tabular}

Tabel diatas adalah tabel yang menunjukkan hasil posttest pada kelas kontrol dengan interval nilai 40 - 45 dengan jumlah frekuensi 3, interval nilai 46 - 51 dengan jumlah frekuensi 2, interval nilai 52 - 57 dengan jumlah frekuensi 2, interval nilai 58 - 63 dengan jumlah frekuensi 0, interval nilai 64 - 69 dengan jumlah frekuensi 7, interval nilai 70 - 75 dengan jumlah frekuensi 16 . Nilai rata-rata nya 66,16 dan standar deviasi 8,57. Untuk lebih jelasnya mengenenai penjabaran nilai setiap siswa dapat dilihat pada lampiran.

Hasil belajar dari kedua kelas setelah diberi perlakuan yaitu posttes, maka dapat digambarkan melalui diagram sebagai berikut : 
Diagram 2

Hasil post test kelas eksperimen dan kelas kontrol

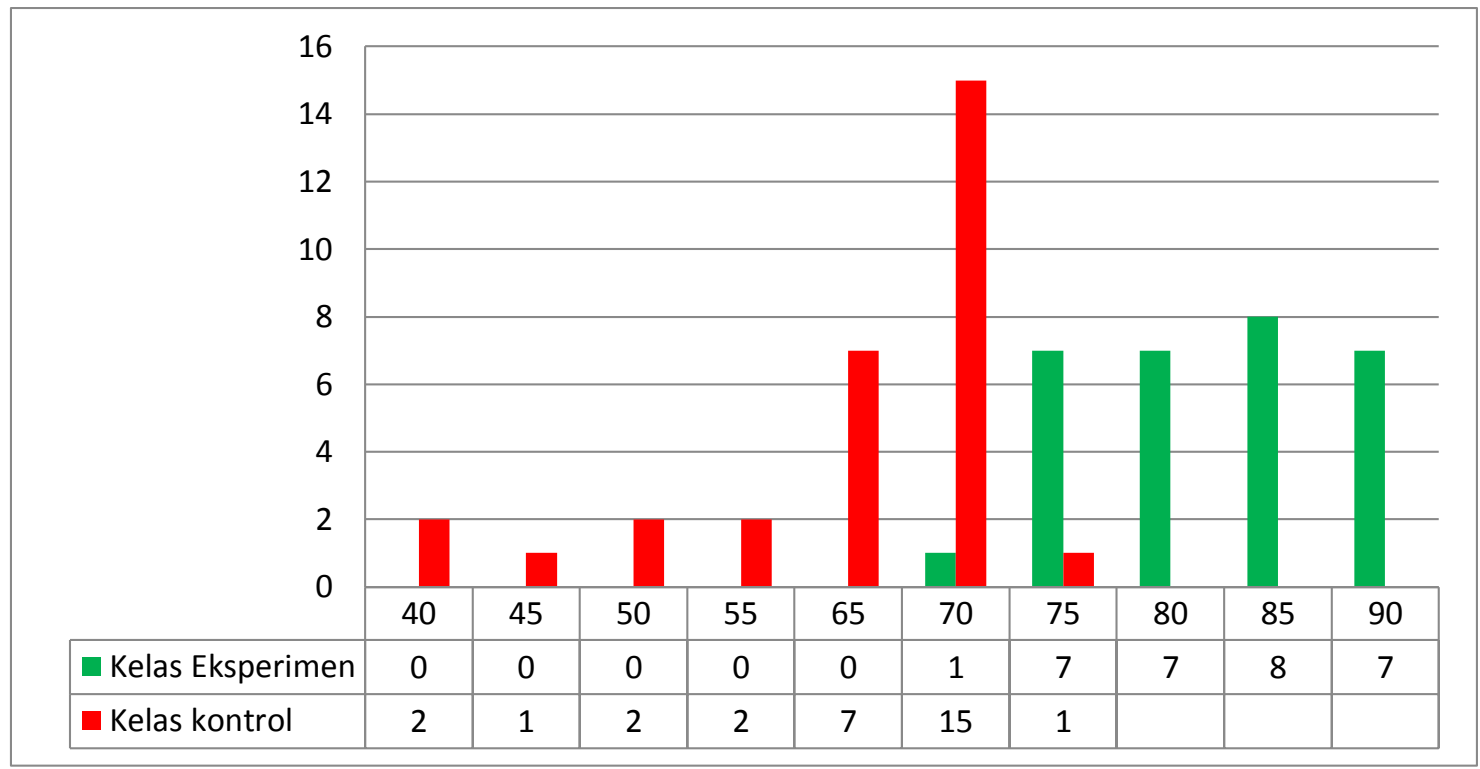

Berdasarkan diagram batang diatas terlihat perbedaan hasil belajar karena telah diterapkannya model pembelajaran Think Pair Share terhadap hasil belajar siswa pada pembelajaran sejarah.

Tabel 6

Uji Normalitas Kelas Eksperimen dan Kelas Kontrol

\begin{tabular}{|l|l|l|l|l|}
\hline \multirow{2}{*}{ Statistik } & \multicolumn{2}{|l|}{ Kelas Eksperimen } & \multicolumn{2}{l|}{ Kelas Kontrol } \\
\cline { 2 - 5 } $\mathbf{N}$ & Pre test & Post test & Pre test & Post test \\
\hline $\mathbf{X}$ & 30 & 30 & 30 & 30 \\
\hline $\mathbf{S}$ & 52,6 & 81,2 & 54,3 & 66,16 \\
\hline Lhitung & 7,9 & 11,6 & 9,7 & 8,57 \\
\hline Ltabel & 0,1371 & 0,1411 & 0,1512 & 0,1469 \\
\hline Kesimpulan & 0,161 & 0,161 & 0,161 & 0,161 \\
\hline
\end{tabular}


Dari tabel diatas menunjukkan hasil uji normalitas untuk kedua kelas yaitu kelas eksperimen dengan data pretest dan posttest berdistribusi normal begitu juga dengan kelas kontrol data pretest dan posttest berdistribusi normal karena Lhitung < L tabel.

Tabel 7

Hasil Uji Homogenitas Kelas Eksperimen dan Kelas Kontrol

\begin{tabular}{|l|l|l|l|l|l|}
\hline No & Data Kelas & Varians & Fhitung & Ftabel & Kesimpulan \\
\cline { 1 - 3 } 1. & Pre-test Eksperimen & 62,41 & 1,50 & 1,86 & Homogen \\
\cline { 1 - 3 } 2. & Pre-test Kontrol & 94,09 & & & \\
\hline 3. & Post-test Eksperimen & 134,5 & 1,83 & 1,86 & Homogen \\
\cline { 1 - 3 } 4. & Post-test Kontrol & 73,44 & & & \\
\hline
\end{tabular}

Tabel diatas hasil dari uji homogenitas dari kedua kelas, yaitu dari hasil pre-test dan post-test kelas eksperimen bersifat homogen, begitu juga hasil pre-test dan post-test kelas kontrol juga bersiat homogen. Hal ini sesuai dengan kriteria yaitu Fhitung < Ftabel, maka dari hasil diatas nilai pre-tes dan pos-test untuk keseluruhan Fhitung < Ftabel dan bersifat homogen.

Tabel 8

Hasil Uji Hipotesis Pre-test Siswa

\begin{tabular}{|l|l|l|l|l|l|}
\hline No & Data Kelas & $\begin{array}{l}\text { Nilai Rata- } \\
\text { Rata }\end{array}$ & Thitung & Ttabel & Kesimpulan \\
\hline 1. & $\begin{array}{l}\text { Kelas } \\
\text { eksperimen }\end{array}$ & 52,6 & 0,8015 & 1,6723 & $\begin{array}{l}\text { Pengetahuan } \\
\text { awal siswa } \\
\text { antara kelas } \\
\text { eksperimen dan } \\
\text { kelas kontrol } \\
\text { sama }\end{array}$ \\
\hline 2. & Kelas Kontrol & 54,3 & & & \\
\hline
\end{tabular}

Tabel diatas adalah hasil dari uji hipotesis pre-test siswa dari kelas eksperimen dan kontrol, diperoleh Thitung 0,8015 dan Ttabel adalah 1,6723. Kriteria hipotesis yaitu jika Thitung < Ttabel, Thitung 0,8015 < Ttabel 1,6723, maka H0 diterima yaitu pengetahuan awal siswa antara kedua sampel sama. Tabel 4.9 
Hasil Uji Hipotesis Post test Siswa

\begin{tabular}{|l|l|l|l|l|l|}
\hline No & Data Kelas & $\begin{array}{l}\text { Nilai Rata- } \\
\text { Rata }\end{array}$ & Thitung & Ttabel & Kesimpulan \\
\hline 1. & $\begin{array}{l}\text { Kelas } \\
\text { eksperimen }\end{array}$ & 81,2 & 6,0645 & 1,6723 & $\begin{array}{l}\text { Ada perbedaan } \\
\text { hasil belajar } \\
\text { yang signifikan, } \\
\text { yaitu hasil } \\
\text { belajar kelas } \\
\text { eksperimen lebih } \\
\text { tinggi daripada } \\
\text { kelas kontrol }\end{array}$ \\
\hline 2. & Kelas Kontrol & 66,16 & & & \\
\hline
\end{tabular}

Tabel diatas adalah hasil dari uji hipotesis post-test siswa dari kelas eksperimen dan kelas kontrol, diperoleh Thitung 6,0645 dan Ttabel adalah 1,6723 (ini dapat dilihat dari tabel t pada taraf signifikan 0,05). Kriteria hipotesis yaitu jika Thitung > Ttabel, Thitung 6,0645 > Ttabel 1,6723, maka Ha diterima yaitu hasil belajar yang signifikan dan lebih tinggi dari kelas kontrol. Dapat disimpulkan ada perbedaan akibat pengaruh model Think Pair Share terhadap hasil belajar sejarah siswa.

Dari hasil pengujian hipotesis bahwa ada perbedaan antara hasil belajar yang menggunakan model pembelajaran Think Pair Share dengan menggunakan metode ceramah. Hal ini dapat dilihat dari hasil belajar siswa. Hasil belajar dari sebelum diberikan perlakuan, nilai rata-rata pretest siswa kelas eksperimen 52,6 dan setelah diberikan perlakuan dengan menggunakan model Think Pair Share nilai rata-rata post test pada kelas eksperimen yaitu 81,2. Sedangkan hasil belajar siswa pada kelas kontrol rata-rata sebelum diberi perlakuan yaitu 54,3. Setelah diberi perlakuan yakni dengan menerapkan metode pembelajaran dengan ceramah nilai rata-rata adalah 66,16.

Perbedaan yang signifikan tersebut dikarenakan oleh beberapa faktor dimana pada kelas kontrol, siswa menggunakan model pembelajaran konvensional. Guru aktif memberikan penjelasan terperici tentang materi, mengelolah dan mempersiapkan bahan ajar, kemudian menyampaikannya kepada siswa. Sebaliknya siswa berperan pasif tanpa banyak melakukan kegiatan. Seringkali siswa yang pandai merasa dirinya 
mampu menyelesaikan tugas sendiri, siswa yang kurang pandai hanya menyalin pekerjaan siswa yang pandai sehingga membuat siswa yang kurang pandai merasa kurang percaya diri dalam menyamaikan pendapatnya. Dengan pembelajaran konvensional (ceramah) hanya diberikan penjelasan materi dan memberikan kesempatan untuk bertanya yang belum tentu mereka mengerti dengan penjelasan guru yang ada didepan. Lebih cenderung gurunya yang lebih aktif sehingga siswa nya kurang bersemangat, tidak mau mendengarkan dan kadang mengantuk pada saat pembelajaran sedang berlangsung.

Sedangkan dikelas eksperimen pembelajaran yang dilakukan dengan memberikan model pembelajaran Think Pair Share. Model pembelajaran Think Pair Share yaitu suatu model pembelajaran yang berpusat pada siswa (student centered). Model Think Pair Share membantu siswa menemukan ide mereka bersama dan memperbaiki pemahaman. Dengan model Think Pair Share, siswa secara langsung dapat memecahkan masalah, memahami suatu materi secara berpasangan, membuat kesimpulan (diskusi) serta mempresentasikan di kelas.

\section{PENUTUP}

Hasil belajar siswa yang dilakukan dengan menggunakan model pembelajaran Think Pair Share di kelas X IIS 1 SMA S Deli Murni Delitua Tahun Pelajaran 2019/2020 dengan nilai rata-rata 81,2, sedangkan hasil belajar siswa yang diajarkan dengan menggunakan metode ceramah di kelas X IIS 2 SMA S Deli Murni Delitua Tahun Pelajaran 2019/2020 dengan nilai rata-rata 66,16. Ada perbedaan yang signifikan hasil belajar siswa yang diajar dengan menggunakan model pembelajaran Think Pair Share dengan siswa yang diajar dengan menggunakan model pembelajaran ceramah. Hal itu terlihat pada hasil belajar siswa yang diajar dengan menggunakan model pembelajaran Think Pair Share nilainya lebih tinggi serta siswa ikut berperan aktif dalam kegiatan pembelajaran dan mereka dapat memahami dengan mudah setiap pembelajaran serta bisa mengambil manfaat dari materi sejarah tersebut dibandingnkan dengan kelas yang diajar dengan menggunakan model ceramah cenderung hanya 
beberapa siswa saja yang terlihat aktif selebihnya mereka hanya mengetahui dan membaca dari buku dan materi yang diterangkan guru didepan.

\section{REFERENSI}

Arifin, Johar. (2017). SPSS 24 untuk penelitian dan Skripsi. Jakarta : Kompas Gramedia.

Arikunto. (2010). Prosedur penelitian suatu pendekatan praktik. Jakarta : Rineka Cipta.

Hamdani. (2011). Strategi Belajar Mengajar.Bandung : CV PUSTAKA SETIA.

Hamdayana, Jumanta. (2017). Model Dan Metode Pembelajaran Kreatif Dan Berkarakter. Bogor: GHALIA INDONESIA.

Istarani. (2012). 58 Model Pembelajaran Inovatif. Medan : Media Persada.

Matondang, Zulkifli. (2009). Evaluasi Pembelajaran. Medan : Program Pacsa Sarjana UNIMED.

Milfayetty Sri dkk.(2018). Psikologi Pendidikan. Medan : Pps Unimed.

Rusman. (2012). Model-model pembelajaran. Jakarta: Raja grafindo Persada.

Sagala, Syaiful. (2009). Konsep Dan Makna Pembelajaran. Bandung : Alfabeta.

Shoimin, Aris. (2014). Model Pembelajaran Inovatif Dalam Pembelajaran Inovatif Kurikulum 2013. Jakarta : AR-RUZZ MEDIA.

Sudjana, Nana. (2002). Penilaian Hasil Proses Belajar Mengajar.Bandung : PT REMAJA ROSDAKARYA.

Sugiyono. (2015). Metode Penelitian Pendidikan Pendekatan Kuantitatif Kualitatif dan $R \& D$. Bandung: Alfabeta.

Tanjung, Yushar. (2014). Pendidikan Sejarah Suatu Pengantar.Medan : UNIMED.

Trianto. (2009). Mendesain Model Pembelajran Inovatif-Progresif. Jakarta: Kencana Pernada Media Group. 